\title{
Evidence for cytoplasmic inheritance of a developmental organizer affecting growth habit and leaf shape in Antirrhinum majus
}

\author{
VL Bergbusch \\ Victoria, BC, Canada
}

A cross between two distinct, true-breeding plants of Antirrhinum majus L. showed an unexpected pattern of inheritance of growth habit in the F2, which was extended to both growth habit and leaf shape in the F3 generation of all the plants traced further. All the F3 families, offspring of individual F2 plants, were very uniform for both growth habit and leaf shape traits but differed distinctly from each other in these respects. The backcrosses of selected F3 and F4 families to the original parents in the cross did not segregate for the distinctive family phenotypes. This led to the postulate that a cytoplasmic factor was involved in the regulation and/or integration of genetic information concerned with growth habit/leaf shape. The similarity of the reciprocal backcrosses of the F3 and F4 families led to the further postulate that the proposed cytoplasmic factor was specified by both the maternal and paternal parents to a similar degree. That the gene component was segregating normally was shown by the inheritance of four marker genes for flower colour, colour pattern and flower shape.

Heredity (2002) 89, 44-55. doi:10.1038/sj.hdy.6800100

Keywords: Antirrhinum majus; fixation of growth habit-leaf shape; shoot apical meristems; developmental organizers; cytoplasmic inheritance

\section{Introduction}

Studies of growth habit and leaf shape in plants may reveal their underlying organization, which, in turn, leads to an understanding of the initiation of patterned differentiation. The inheritance of growth habit and leaf shape in Antirrhinum majus has long been known to have many genetic components (Stubbe, 1966). Both growth habit and leaf shape are complex characters not easily quantified for meaningful studies of gene effects, which often affect several measurable characters at once in a complex way, as well as some characters not usually quantified. The extensive studies by Harte and her coworkers on leaf shape mutants in Antirrhinum have shown that a developmental description of leaf form depends not only on a complex relationship between the length and width of a leaf, but also on leaf position on the plant, and that it is controlled by the interaction of genes and environmental factors such as day length and temperature (Harte and Meinhard, 1979, 1980; Harte and Pohl, 1989). She also found that the effects of the mutant genes studied can be traced back to the leaf primordium as it separates from the apical meristem (Harte and Meinhard, 1980; Harte and Pohl, 1989).

Studies of individual gene effects on growth habit in Antirrhinum, as detailed as those on leaf shape, have not

Correspondence: VL Bergbusch, 315-1025 Inverness Road, Victoria, B.C., Canada V8X 2S2. E-mail: yyj00204@direct.ca

Received 29 September 2000; accepted 14 February 2002 been published, but both environmental and genetic effects on growth habit are well known (Stubbe, 1966). The role of shoot apical meristems in the inverse relationship between height and degree of branching, known as apical dominance, is well established (Cline, 1991). Characters such as stem thickness, angle of emergence of branches from the main stem, distribution of branches along the main stem (eg, basal or lateral), relative length of branches at different points along the main stem, can be visually identified in the effects of some genes on growth habit and although visually striking, are neither easily defined nor measured. Similarly, in leaves, differences such as rounded or pointed tip of leaf, upturned, downturned or flat margins of leaves can also be visually striking but are not easily quantified. When classical phenotypic segregation follows gametic genetic segregation, individual phenotypes showing some combination of these characters can be described and counted, and a degree of gene control can be demonstrated even on complex characters.

This study was interested in tracing the inheritance of growth habit and leaf shape characters through several generations of a cross and through reciprocal backcrosses, in order to determine whether it could be attributed solely to the genetic makeup of the plant, or whether there were other components of the plant which played a role, not just in the development of the growth habit/leaf shape complex, but also in its inheritance. The wealth of early material on the role of the shoot apical meristem in the development of growth habit and leaf shape made the inheritance of these characters of particular interest, as the debate on the initiation and control 
of differential gene action in organ development has not as yet been finally resolved.

\section{Materials and methods}

\section{Materials}

Two plant lines were used in these experiments: Sippe 50 lab stock and its two derivatives, the hemiradialis and radialis lines, and the Sheffield plant. The radialis lines were characterized by a tall, very dominant main axis until flowering time. Primary lateral branches developed along the main axis, the most basal branches tending to be longer than those at the top, but never equal to the main axis in length. The main axis remained very distinct and dominant throughout the life of the plant under the conditions applying in these experiments. This phenotype is defined as 'erect' in this paper. Plants grown from selfed seed of these lines were all erect in phenotype. The juvenile leaves were large and rounded, giving way to progressively smaller more pointed adult leaves.

The Sheffield plant was maintained by cuttings during the course of these experiments and was also selfed. The original plant, in contrast to the radialis lines, was shorter and more branched; it had no highly predominant main axis, but had several long, basal branches. The selfed progeny of the Sheffield plant showed the parental phenotype; the basal branches developed early in the juvenile phase of growth, either from initials on the hypocotyl or in the axils of basal leaves. The main axis and the basal branches branched again into secondary lateral branches well before flowering began, and gave the plants a low, densely branched look, even after the elongation the plants showed on flowering; they remained shorter than the inbred lines derived from Sippe 50. This phenotype was described as 'bushy', and all the selfed progeny of the Sheffield plant were also low and bushy in the same way as the Sheffield plant. The juvenile leaves were considerably narrower than those of the inbred lines derived from Sippe 50 though the tips were rounded, and were succeeded by shorter adult leaves in all the progeny.

'Semi-erect' plants were defined as those that showed a dominant seedling axis in the mature plant, some primary lateral branching and one or more well-developed basal branches.

The following four genes carried by these lines are pertinent to the work described (the superscript ' + ' denotes the 'wild type' allele, Stubbe, 1966); they were used as marker genes and controls in the experiments described in this paper.

1. radialis radialis (rad ${ }^{\text {rad }}$ ), radialis hemiradialis $\left(\mathrm{rad}^{\text {hem }}\right)$ and $\mathrm{rad}^{+}$ are a series of alleles affecting the symmetry of the lateral Antirrhinum flower; radrad is recessive to rad hem, which is recessive to the normal allele $\mathrm{rad}^{+}$. They identify chromosome Rad (Stubbe, 1966) and are active at the shoot apical meristem (Bergbusch, 1999).

2. eosinea (eos): eos eos plants form pink pigment, $e o s^{+}-$ plants form magenta pigment in the flowers. The gene identifies one chromosome (Giessmann et al, 1954; Stubbe, 1966).

3. $y^{+}$: the dominant allele, $y^{+}$, suppresses the yellow pigment, aureusidin, everywhere but in the tips of the lower lip lobes and the internal and sub-lip rows of hairs

(Giessmann et al, 1954). It is probably identical with the gene sulfurea ${ }^{+}\left(\right.$sulf $\left.f^{+}\right)$described by Stubbe (1966). There is no evidence for linkage with eos, rad ${ }^{\text {rad }}$ or El.

4. Eluta (El): the dominant allele, $E l$, suppresses magenta (or pink) pigment in the petals by restricting its expression to markings at the base of the adaxial petal lobes and on the abaxial lip lobes; 'wild type' $=E l^{+} E l^{+}$. It also identifies one chromosome (Stubbe, 1966).

The $\mathrm{rad}^{\text {hem }}$, rad ${ }^{\mathrm{rad}}$ genes are in the genetic background of Sippe 50 described by Stubbe (1966) and were obtained from him by Professor JM Thoday. The Sheffield plant was collected from a garden in Sheffield by Professor JM Thoday. It is also $\mathrm{rad}+\mathrm{rad}^{+} \mathrm{El}^{+} \mathrm{El}^{+}$yy eos eos.

\section{Methods}

Plants used as the maternal parent in a cross were emasculated and bagged in a glassine bag well before the flower opened, when the pollen is still immature and the anthers intact. The pollen parent and selfed plants were similarly bagged before flower opening. Classification of the plants for flower shape and flower colour patterns began as soon as the flowers began to open.

Seeds were sown in March in the greenhouse in pots containing a standard sterilized soil mixture. Seedlings were transferred to wooden trays several days after their emergence and hardened off in cold frames in April/May. All the plants for each experiment were sown on the same day and the transfer of the seedlings to trays was accomplished within 2 days. In the transfer, seedlings were gathered from an arbitrarily chosen wedge of soil and each seedling taken in turn from the point outward in strict succession. Randomization in replicates was initiated at the transfer to trays in the greenhouse and carried through to the field planting in late May or June; no replication was done in the original F1 or F2.

The crosses and selfs made using the hemiradialis line are given in the flow chart in Figure 1. The F2 progeny of individual F1 plants will hereafter be called tribes, while the F3 progeny derived from individual F2 plants will be called families. The plants selected for selfing or crossing were taken at random but $\mathrm{rad}^{\text {hem }} \mathrm{rad}^{\text {hem }}$ homozygotes were excluded in selfing the F2 generation in order to increase the proportion of segregating families. Because of the association between determination of flower symmetry and the shoot apical meristem (Bergbusch, 1999), the segregation of this gene was of particular interest. The families from each tribe were randomized over replicates, after random selection of tribal sites within each replicate. The F4 and F5 generation were grown by selfing two (F3) or three (F4) randomly selected plants from each family in succeeding generations.

Reciprocal backcrosses of typical F3 (pilot experiment), and reciprocal backcrosses and intercrosses of F4, families were made using randomly selected plants from arbitrarily chosen F3/F4 families and the two original parents in the cross. Several backcross (B1) and intercross (T1) generations were grown over a period of several years, one being a complete diallel (Table 1). All backcross tests after the first pilot test included the F1 generation as well as the selfs of the original parents and the F4 families for comparison.

To test the visual observations, several traits which could be quantified were measured in the F3: plant height 


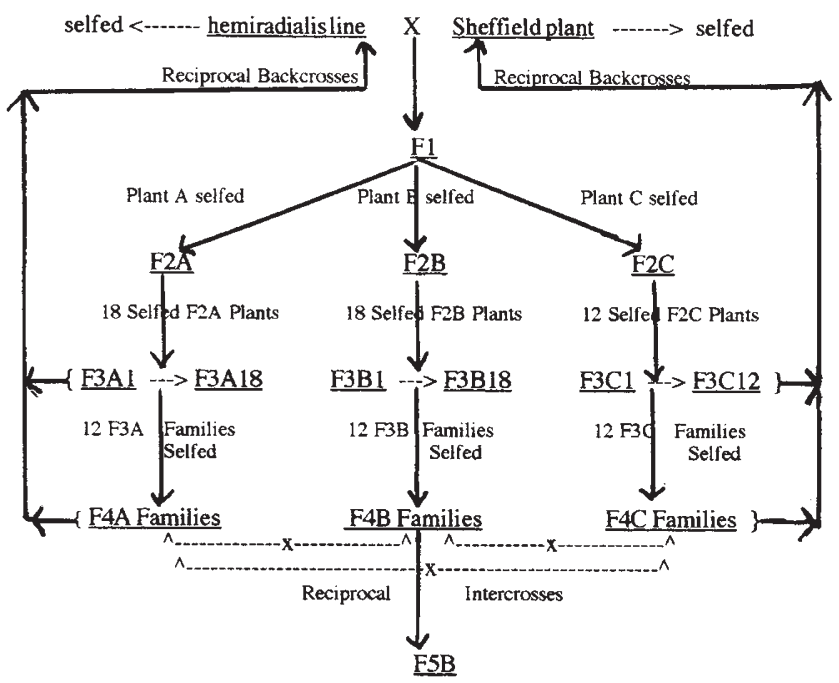

Figure 1 Flow chart of selfs, backcrosses and intercrosses made following the cross between the hemiradialis line and the Sheffield plant shown at the top. The solid lines and arrows pointing downward, and sideways and downward, indicate the succession of selfs made following the initial cross - F2 to F5 - in the progeny of three F1 plants followed further. The arrows pointing sideways and upwards indicate the two sets reciprocal backcrosses, using either F3 or F4 families, made to the original parents in the cross, while the dotted lines pointing sideways only, near the bottom of the chart, indicate the reciprocal intercrosses made for the complete diallel experiment. The dotted lines at the top indicate the control selfs of the original parents in the cross.

Table 1 Detail of reciprocal backcrosses and intercrosses of F4 families, the radhem line and the Sheffield plant, for the simulated diallel experiment

\begin{tabular}{lllllll}
\hline $0^{4}$ & F4A & F4B1 & F4B2 & F4C & P1(hem) & P2 (She) \\
\hline & & & & & & \\
F4A & self A & IC & IC & IC & BC & BC \\
F4B1 & IC & self B1 & IC & IC & BC & BC \\
F4B2 & IC & IC & self B2 & IC & BC & BC \\
F4C & IC & IC & IC & self C & BC & BC \\
P1 (hem) & BC & BC & BC & BC & self P1 & F1 \\
P2 (She) & BC & BC & BC & BC & F1 & self P2 \\
\hline
\end{tabular}

$\mathrm{IC}=$ intercrcross $; \mathrm{BC}=$ backcross; $\mathrm{P} 1, \mathrm{P} 2=$ original parents in cross.

$(\mathrm{H})$, plant breadth $(\mathrm{B})$, leaf length $\left(\mathrm{L}_{1}\right)$, maximum leaf width $(W)$, and leaf length from tip to point of maximum width $\left(L_{2}\right)$. Measurements of plants for height and breadth were carried out over 1 to 2 days and taken near the onset of flowering, except for the F5 and the complete diallel, when they were measured at the greenhousegrown juvenile stage just prior to sampling for leaf shape. Plant breadth was defined as the mean of two maximum measurements taken at right angles to each other. These measurements, except for the breadth measurement, were collected for all the succeeding generations. Leaves were collected over a period of 1 to 2 days maximum for individual experiments also; they were printed by pressing them on an ink pad, then on a sheet of paper. Measurements were taken from the prints. For most of the experiments, three leaves per plant were taken from maturing plants; not all families matured at the same time and this served to differentiate families also. The leaves were taken more or less at random, by making three separate blind stabs at the plant from the same distance and height. In two of the experiments (ie, the diallel and the F5), only two leaves were sampled and these were fixed as the second pair of juvenile leaves, taken from juvenile plants before transfer to the field.

Means and 95\% confidence intervals of each measurement were calculated for all the F3 families and for the backcrosses and intercrosses. An analysis of variance was done on each measurement taken plus the following ratios: $\mathrm{H} / \mathrm{B}$ and $\mathrm{L}_{1} / \mathrm{W}$; and an analysis of covariance was applied to the F3 leaf length and width data. Wearden's diallel analysis (Wearden, 1964) for maternal effects was applied to the data collected in the diallel experiment.

A second cross, between the radialis line and the Sheffield plant, was grown for an F1, F2 and F3 as in the first cross. Only three F1 plants were carried forward for the F2 generation. The growth habit and leaf shape characteristics of the F1 in this cross were essentially identical to those of the parallel F1. An F3 generation was derived from the F2 by selfing 18 randomly selected plants (excluding those homozygous $\mathrm{rad}^{\mathrm{rad}} \mathrm{rad}^{\mathrm{rad}}$, as above) from each of the three F2 progeny ( $D, E, F$ tribes). It is described in less detail than the parallel cross and is used mainly for comparison and confirmation of the earlier results from the hemiradialis $\times$ Sheffield cross. In this set of crosses, both the F2 and F3 generations were grown in randomized replicates.

\section{Results}

The radialis hemiradialis line $\times$ the Sheffield plant : $\mathrm{rad}^{\text {hem }} \mathrm{rad}^{\text {hem }} \mathrm{EIEl} \mathrm{y}^{+} \mathrm{y}^{+} \operatorname{eos}^{+} \mathrm{eos}^{+} \times \mathrm{rad}^{+} \mathrm{rad}^{+} \mathrm{El}^{+} \mathrm{El}{ }^{+}$yy eos eos $^{+}$

The F1 hybrid of this outcross was uniformly erect; its height was close to that of the hemiradialis line (Table 2). The phenotype of the F1 showed dominance of the inbred line in most characters; variation appeared in the intensity of anthocyanin flush in the petals. Of the $10 \mathrm{~F} 2$ tribes, one (A) showed no segregation for growth habit; it was very 'erect', with very sparse branching appearing at the time of flowering. No bushy segregants were found in a total of 178 plants, though they grew beside bushy tribes. At the other extreme were several 'bushy' tribes, which branched early in the vegetative period of growth; these showed variation in type of branching, eg, almost exclusively basal, or basal and lateral to various degrees, with or without secondary lateral branching; they resembled each other only in being both relatively low and highly branched types throughout their lifetime. The bushy F2 tribe (C) selected for further study contained 139 plants, none of which was erect. Both the erect and bushy tribes showed variation in leaf shape between plants, the bushy more than the erect.

The remaining F2 tribes were variable with respect to type and degree of branching and leaf shape. In some tribes no two plants appeared identical with respect to all these traits (eg, the B tribe). The total amount of morphological variation released by this outcross was very large and can be partially visualized by scanning the photographs of individual plants characteristic of several F3 families (Figure 2). Segregation for the four marker genes was normal in all 10 F2 tribes. 
Table 2 Sample mean growth habit and leaf shape measurements $(\mathrm{cm}) \pm 95 \%$ confidence intervals for the F1 and the parent lines, rad ${ }^{\text {hem }}$ and Sheffield

\begin{tabular}{|c|c|c|c|c|}
\hline & Mean leaf length & Mean leaf width & Mean leaf ratio & Mean height \\
\hline \multicolumn{5}{|l|}{ Juvenile plants ${ }^{\mathrm{a}}$} \\
\hline hemiradialis & $2.2 \pm 0.049$ & $1.4 \pm 0.037$ & $1.6 \pm 0.025$ & $19 \pm 1.1$ \\
\hline Sheffield & $2.0 \pm 0.077$ & $1.1 \pm 0.037$ & $1.8 \pm 0.043$ & $14 \pm 0.79$ \\
\hline rad $^{\text {hem }} \times$ Sheff. & $2.2 \pm 0.057$ & $1.4 \pm 0.037$ & $1.6 \pm 0.025$ & $21 \pm 1.3$ \\
\hline \multicolumn{5}{|l|}{ Mature plants ${ }^{\mathrm{a}}$} \\
\hline hemiradialis & $3.2 \pm 0.107$ & $0.66 \pm 0.032$ & $5.1 \pm 0.176$ & $41.3 \pm 1.39$ \\
\hline Sheffield & $2.6 \pm 0.083$ & $0.60 \pm 0.025$ & $4.5 \pm 0.160$ & $25.3 \pm 0.95$ \\
\hline $\mathrm{rad}^{\text {hem }} \times$ Sheff. & $3.2 \pm 0.087$ & $0.70 \pm 0.032$ & $4.9 \pm 0.158$ & $35.7 \pm 1.25$ \\
\hline
\end{tabular}

aThese data are not taken from the original F1 but from samples tested in other experiments in later years; the juvenile plants were taken from the diallel experiment, the mature plants from a later repeat of a number of backcrosses. The second leaf pair was measured in the juvenile phase, while three leaves were taken at random for the mature leaves.

The 48 F3 families gave an unusual picture of the inheritance of leaf shape and growth habit. Each F3 family was highly characteristic for both, but little or no segregation for either character occurred within families, when compared with the distinctions between families. This was true in the $A$ and $C$ tribes as well as in the $B$ tribe (Figure 2). Although the quantitative measures overlapped between families (Table 3), they added to the visual effect of the qualitative traits for a total morphological phenotype which appeared to be inherited as a unit.

It is obvious from the F-values testing significance of between family-within tribe differences in mean height (Table 4), that families are highly differentiated for this character. The analyses of the quantitative data presented in this paper are representative of the phenomenon described; analyses of the other measurements taken showed the same result, and were equally significant statistically $(P<0.001)$. Traits which were not quantified, such as: pointed or rounded tip of leaf, upturned or downturned margin of leaf, basal vs lateral branching and mixtures thereof, diameter of stem and branches, angle of emergence of branches, were highly characteristic traits in the comparison of families visually.

A major part of leaf shape variance within families was due to within plant variation from juvenile leaf to adult; the sample taken at random from each plant (three leaves) was too small to average out in comparing plants, but the whole sample from a family was probably large enough (90 leaves) to describe the family accurately at the plant level (Figure 3). A characteristic and significant linear regression of leaf length on leaf width within families was found (data not given). The analysis of covariance of length and width (Table 5) shows significant differentiation of the regression coefficients among families in tribes $\mathrm{A}$ and $\mathrm{B}$ but not in tribe $\mathrm{C}$. In each tribe the adjusted means are very significantly differentiated too although they are critically tested only in Tribe C, because only here is there no significant differentiation of regression coefficients. Significant differentiation among families was also found in the separate analyses of leaf length and width and the leaf ratio $\mathrm{L} / \mathrm{W}(P<0.001$; data not given). Significant heterogeneity of variance was detected between families in the deviations from regression. Tests for homogeneity of variance among families within tribes gave highly significant $\chi^{2}$ - values for most of the quantitative traits measured (Bartlett's test for homogeneity of variance, as given by Snedecor, 1956).
The gross significance of the F-values measuring differences among family means, together with the visual observations, strongly suggest that these are real differences. They indicate that little visible phenotypic segregation is occurring between plants within F3 families for growth habit and leaf shape types, but that each selfed family behaves as though it were a distinct population with its own characteristic means and variances for the characters quantified (Figure 3).

Inheritance of the four marker genes was essentially normal in the F3, with some qualifications. The number of families per tribe segregating for each of the four genes was counted, and a $\chi^{2}$ for homogeneity among the segregating families within tribes was calculated; the corresponding $\chi^{2}(3: 1)$ were based on the tribal totals where homogeneity was indicated. Though ratios were sometimes significantly different from those expected on a Mendelian basis, eg, a shortage of hemiradialis segregants in Tribe A, the marker genes indicated overall that normal segregation was still occurring at the chromosomal level (data not given). Preliminary cytological examination of the F2 pollen mother cells also showed normal chromosomal segregation. These results suggest that segregation for growth habit and leaf shape genes was also normal, but its expression suppressed. This was termed 'fixation' of phenotypic character, which had progressed from presumably no fixation in the F1 to almost complete fixation of growth habit and leaf shape in the F3 generation.

The F4 behaved exactly as the F3 had done, with significantly differentiated family means but also heterogeneity of variance. An F5 was grown from 10 families of the $\mathrm{B}$ tribe and similar results were obtained. Choice of directly comparable leaves from each plant did not correct the heterogeneity of variance found in earlier generations (data not given). Phenotypic fixation in these families was virtually unchanged from the F3 generation onward.

A general similarity of morphological types from one generation to the next was observed. Thick-stemmed families tended to remain thick-stemmed, very erect tall families usually produced similar progeny, large-leaved families produced progeny with large leaves, etc. Some changes in growth habit - leaf shape phenotypes were observed from generation to generation; these may have been environmentally as well as genetically induced, as conditions in the field from year-to-year were not identical. 

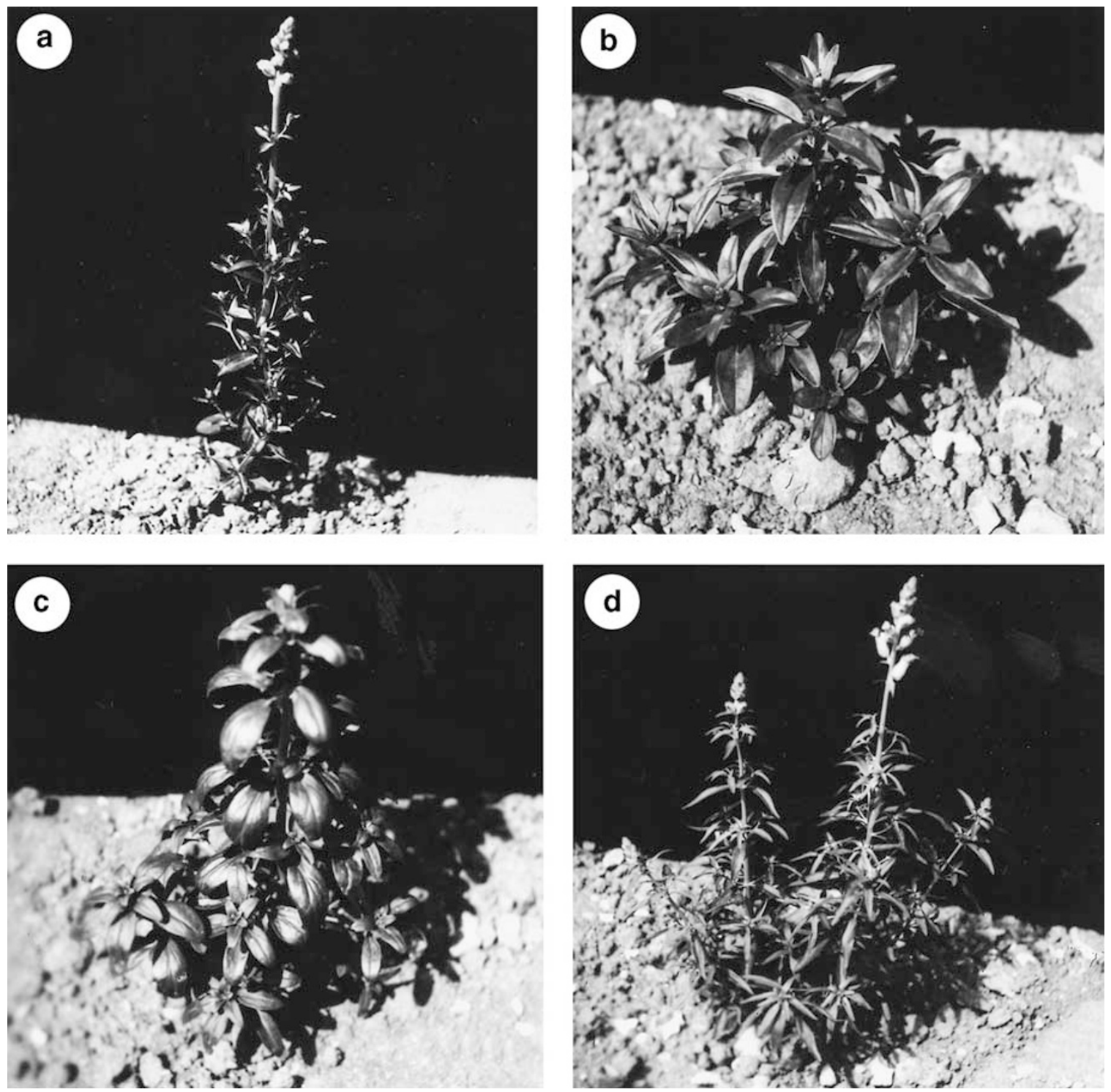

Figure 2 (a) A very erect unbranched family from F3-Tribe A. This family resembled the highly unbranched F2-A population most closely. Leaves are relatively small and pointed. (b)A thick-stemmed, basally branched plant from a very uniform F3-Tribe B family. These plants became very long stemmed on flowering, and showed the exclusively basally branched character clearly then. Juvenile leaves were large, pointed and invariant within the family. (c)A thick-stemmed, erect F3-Tribe B family. Thick stems such as these were characteristic of some Tribe B families. Note the broad, rounded, down-turned leaves. (d) A thin-stemmed, basally-branched F3-Tribe C family. The suppression of lateral branching was not as acute as that in the family in (b). Note the long narrow leaves with upturned margins and pointed tips characteristic of this family. These pictures were all taken within one day for comparison.

The radialis ${ }^{\text {radialis }}$ line $\times$ the Sheffield plant: rad $^{\text {rad }}$ rad $^{\text {rad }}$ EIEl $y^{+} y^{+} \operatorname{eos}^{+} \operatorname{eos}^{+} \times \mathrm{rad}^{+} \mathrm{rad}^{+} \mathrm{El}^{+} \mathrm{Il}^{+}$yy eos eos

To test for consistency of results recorded in the first cross, the F3 derived from the cross, radialis ${ }^{\text {rad }}$ line $\times$ Sheffield plant, was analysed. The F2 segregated for growth habit and leaf shape phenotypes but the range was not as wide as in the original, parallel F2, with respect to thickstemmed, large-leaved types. This may be due to the smaller number of F1 plants sampled in this particular experiment. However it held true for other F2 populations grown at a later date. No F2 progeny failed to segregate for growth habit. One of the F2 progeny in this cross, Tribe E, also segregated for an extreme dwarf phenotype, in a ratio close to a 3:1. Neither of the selfed grandparents segregated for this dwarf.
Except for segregation for dwarf in a few families, the F3 families of the E tribe resembled those of the D and $F$ tribes with respect to growth habit and leaf shape; the quantitative measurements taken significantly differentiated the families in the three tribes $(P<0.001)$ and the three tribes also, substantiating the visual observations (data not given). Marker genes segregated in a reasonably predictable way within families although segregation ratios for some of the tested genes deviated significantly from Mendelian ratios in both the F2 and F3 (data not given), whereas within-family growth habit and leaf shape differences were severely muted or non-segregant, relative to between-family differentiation. It was difficult to judge whether the within family variation was as severely repressed in these three sets of families as those in the $\mathrm{A}, \mathrm{B}$, and $\mathrm{C}$ tribes, as they were grown in different 


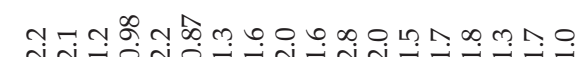

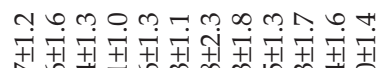

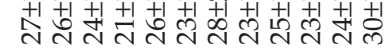

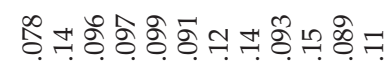

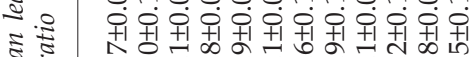

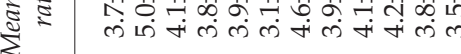

ङ छ

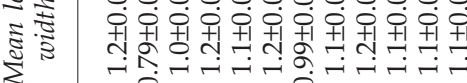

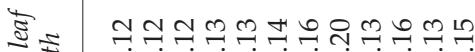

ह

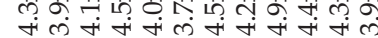

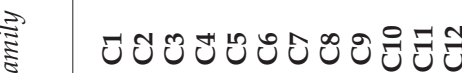

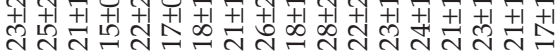

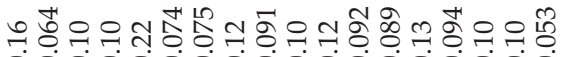

こ

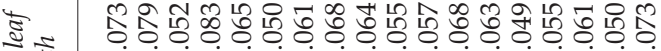

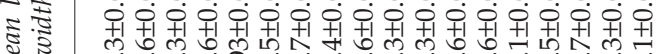

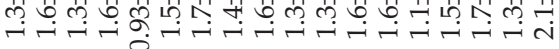

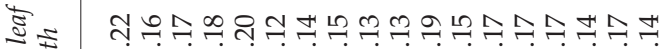

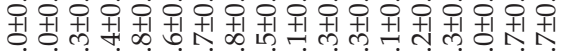

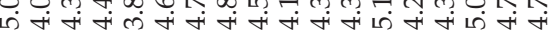

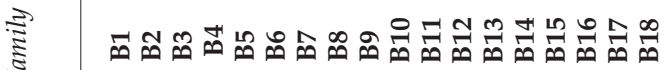

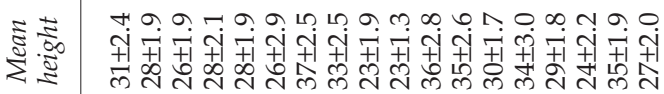

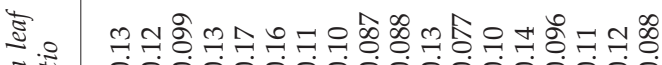

ह

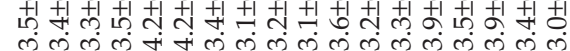

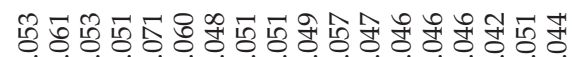

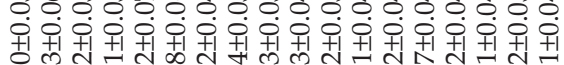

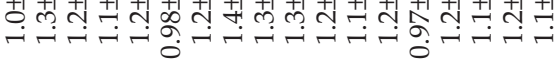

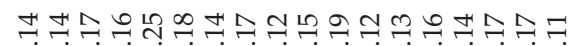

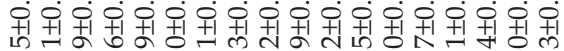

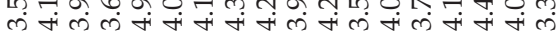


Table 4 Analysis of variance of plant height for the F3 generation from the cross, rad $^{\text {hem }}$ rad $^{\text {hem }} \times$ Sheffield

\begin{tabular}{|c|c|c|c|}
\hline Source of variation & $\begin{array}{l}\text { Degrees of } \\
\text { freedom }\end{array}$ & $\begin{array}{l}\text { Sum of } \\
\text { squares }\end{array}$ & $\begin{array}{l}\text { Mean } \\
\text { square }\end{array}$ \\
\hline Between tribe & 2 & 17640.13 & 8820.1 \\
\hline $\begin{array}{l}\text { Between family, within } \\
\text { tribe }\end{array}$ & 45 & 19330.00 & 429.6 \\
\hline Between replicate & 1 & 346.75 & 346.8 \\
\hline Residual & 1553 & 37101.25 & 23.9 \\
\hline \multicolumn{4}{|c|}{$\begin{array}{l}\text { Between tribe/ between family-within tribe }=20.53^{* * *} \\
\qquad P<<0.001\end{array}$} \\
\hline \multicolumn{4}{|c|}{$\begin{array}{l}\text { Between family-within tribe } / \text { residual }=17.98^{* * *} \\
\qquad P<<0.001\end{array}$} \\
\hline \multicolumn{4}{|l|}{ Tribe $A$} \\
\hline Between family & 17 & 10241.44 & 602.4 \\
\hline Residual & 514 & 17896.87 & 34.8 \\
\hline \multicolumn{4}{|c|}{$\begin{array}{l}\text { Between family } / \text { residual }=17.30^{* * *} \\
\qquad P<<0.001\end{array}$} \\
\hline \multicolumn{4}{|l|}{ Tribe $B$} \\
\hline Between family & 17 & 6220.19 & 365.9 \\
\hline Residual & 516 & 11058.06 & 21.4 \\
\hline \multicolumn{4}{|c|}{$\begin{array}{l}\text { Between family } / \text { residual }=17.07^{* * *} \\
\qquad P<<0.001\end{array}$} \\
\hline \multicolumn{4}{|l|}{ Tribe C } \\
\hline Between family & 11 & 2868.44 & 260.8 \\
\hline Residual & 525 & 12494.50 & 23.8 \\
\hline $\begin{array}{l}\text { Between family/residua } \\
\qquad \mathrm{P}<<0.001\end{array}$ & $10.96^{* * *}$ & & \\
\hline
\end{tabular}

years and were thus not directly comparable. The range of growth habit/leaf shape types seemed narrower here, apart from the dwarf phenotype; hence the within family repression of growth habit/leaf shape variation was not as striking visually. The coefficient of variation $(C)$ for height for the $\mathrm{F} 3 \mathrm{~A}, \mathrm{~B}, \mathrm{C}$ population in total was $27 \%$ $(s=6.82$, mean height $=25)$; while that for the F3 D,E,F population was $38 \%$ ( $s=8.73$, mean height $=23$ ). That the larger coefficient was in the F3 D,E,F population held true also for coefficients calculated on between family/within tribe variation $(130 \%$ and $82 \%)$ and within-family variation $(28 \%$ and $21 \%)$. It was reversed only for between tribe variation, where $\mathrm{C}$ for $\mathrm{F} 3 \mathrm{~A}, \mathrm{~B}, \mathrm{C}$ was $375 \%$ and $\mathrm{C}$ for F3 D,E,F was 337\%. The difference may be largely due to the miniature dwarf segregating in the F3 D,E,F population in the first three instances, both between and within families. The coefficients calculated at each level of the hierarchy for the two populations are of the same order, except perhaps for the between family/within tribe variation, and suggest that the two populations were behaving essentially in the same way. A sample C for the mature radhem line was $23 \%$ and for the Sheffield plant $17 \%$.

\section{Reciprocal backcrosses of selected F3 and F4 families from the original cross to the radialis ${ }^{\text {hemiradialis }}$ line and the Sheffield plant}

The backcrosses in the pilot experiment produced no segregants for F3 growth habit-leaf shape phenotypes in the backcross population, B1. The backcross progeny were as uniform in type as the concomitantly sown F4 and the selfs of the original parents. They were bushy to semierect in the backcrosses to the Sheffield plant; and semierect to erect in the backcrosses to the hemiradialis line. All the backcross progeny were vigorously branched. Leaf shape varied somewhat from backcross to backcross but tended to be intermediate between the two lines in the cross and very uniform within backcross progeny. Visual and quantitative examination of the backcross progeny also showed that no significant reciprocal differences in basic phenotype were present; that is, a consistent maternal effect on growth habit-leaf shape type was not detected. Segregation for flower shape and flower colour and colour pattern genes was normal in the backcrosses where such segregation was expected (data not given).

The model used to test more extensively for consistent maternal effects in the diallel experiment is that given by Wearden (1964) for $p$ fixed parental lines.

$$
\begin{array}{lrl} 
& \mathrm{df} & \multicolumn{1}{c}{\text { E(M.S.) }} \\
\text { Maternal arrays } & p-1 & \sigma^{2}+\mathrm{p} \tilde{\sigma}_{\mathrm{g}}^{2}+\mathrm{p} \tilde{\sigma}_{m}^{2} \\
\text { Paternal arrays } & p-1 & \sigma^{2}+\mathrm{p} \tilde{\sigma}_{\mathrm{g}}^{2}
\end{array}
$$

$F=$ Maternal arrays M.S./Paternal arrays M.S.

The diallel analyses for the three measurements $L_{1}, W$, and $H$, as well as the ratio $L_{1} / W$, are given in Table 6 . The results indicate no significant maternal inheritance; some residual reciprocal differences persisted but these all seemed secondary to the main effect and may not be indications of maternal inheritance at all, but of phenotype-environment interactions and variable for this reason (Jinks, 1954). As a test of the significance of the means, the means and 95\% confidence intervals of the means for height are sampled for both the separated and combined reciprocals and the selfs of the diallel experiment (Table 7). This table shows typical significant differences between the selfed F4 families and between the two original parents but relatively little difference between reciprocal backcrosses to either parent; the distinction between different sets of F4 backcrosses seems to be less than that between the selfs too, in most cases. The distinctions between the backcrosses to the Sheffield plant, as compared to those to the radialis line, are the only consistently significant differences among the crosses.

Further testing of the selfs and backcrosses of F3 and F4 families of the hemiradialis by Sheffield cross have only served to reinforce the conclusions drawn thus far. Not only were there no distinctive segregants in the repeated testing, but comparison of the means of the reciprocal backcrosses for the measurements taken, reinforced the conclusion that this was not a case of maternal inheritance (data not given). Although only a small number of families were tested in backcrosses, the families were representative of the variation seen in the original F2 and F3 populations. No clear cut segregant, which approximated the direct comparisons made with the selfed families and the original parents in the backcross experiments, was seen in any of these backcrosses. The number of plants tested in each F3/F4 family is listed in Table 8 .

\section{Discussion}

The concomitant fixation within families of many of the 
a

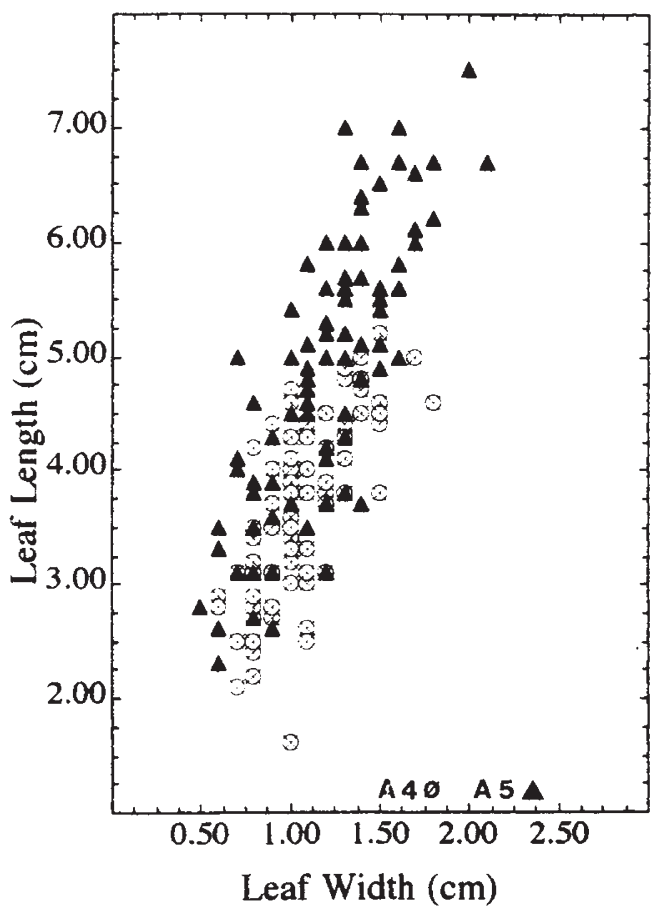

C

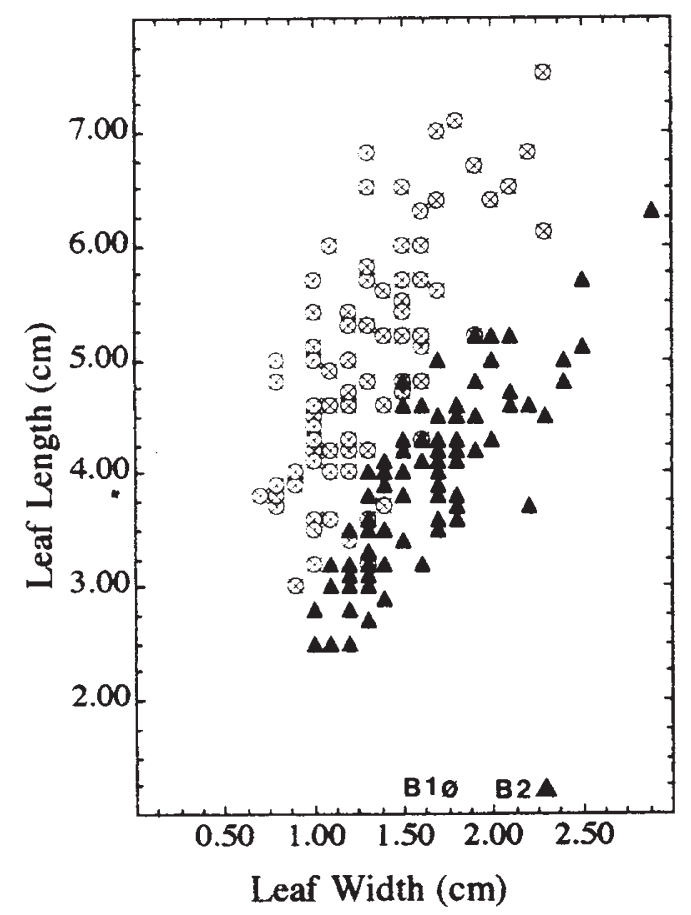

b

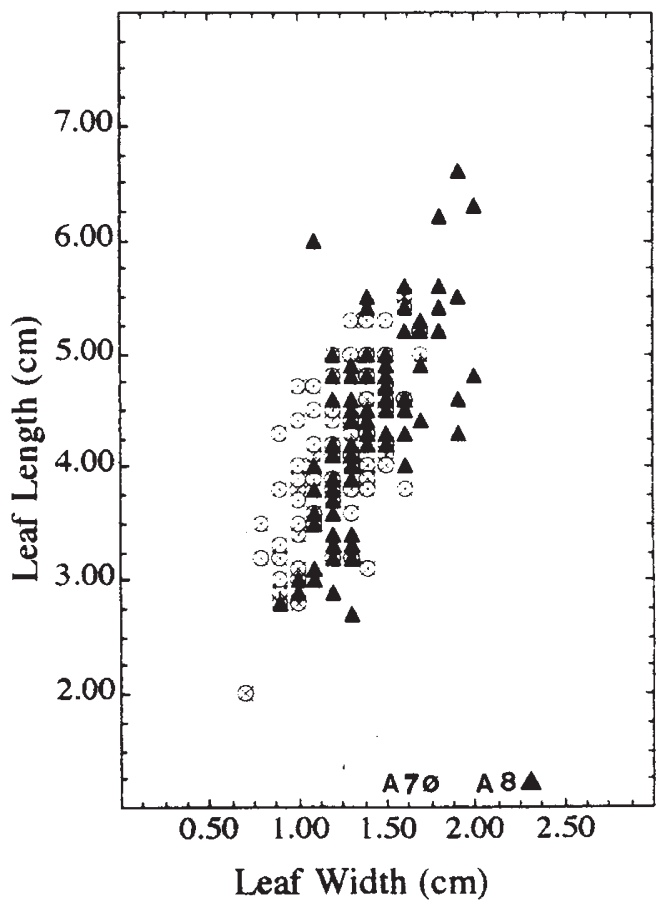

d

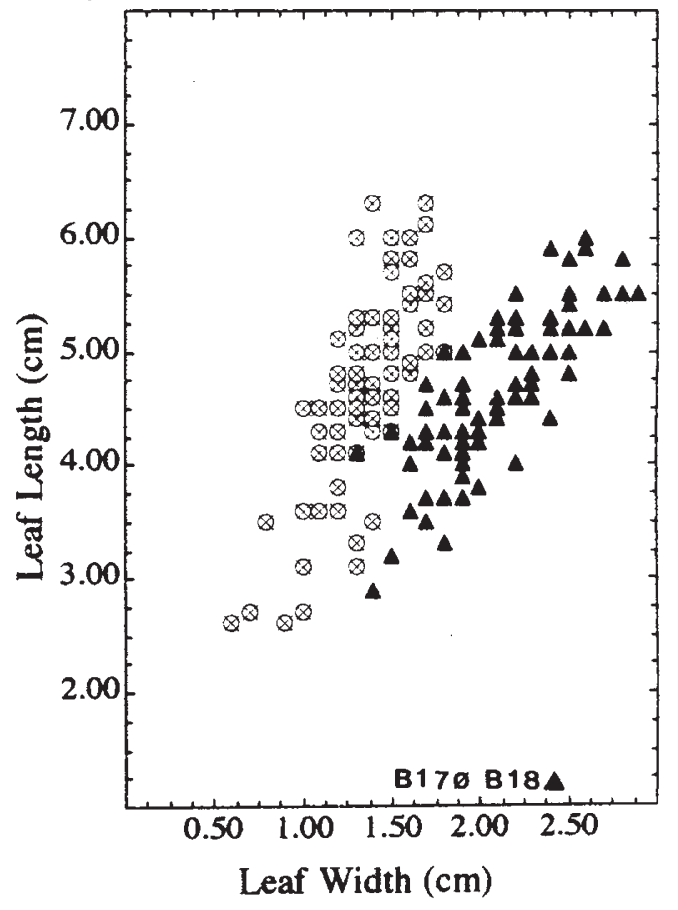

Figure 3 Plots of leaf length $v$ s leaf width in several F3 families from Tribes A and B, taken in pairs. (a) Tribe A, Families 4 \& 5: 4, regression coefficient $=2.22 \pm 0.235$, linear correlation coefficient $=0.710 ; 5$, regression coefficient $=2.75 \pm 0.236$, linear correlation coefficient $=0.778$. (b)Tribe A, Families $7 \& 8: 7$, regression coefficient $=1.96 \pm 0.241$, linear correlation coefficient $=0.653$; 8 , regression coefficient $=2.33 \pm 0.268$, linear correlation coefficient $=0.680$. (c) Tribe B, Families $1 \& 2$ : 1 , regression coefficient $=2.07 \pm 0.225$, linear correlation coefficient $=0.700 ; 2$, regression coefficient $=1.70 \pm 0.124$, linear correlation coefficient $=0.824$. (d)Tribe B, Families 17 \& 18: 17, regression coefficient $=2.43 \pm 0.25$, linear correlation coefficient $=0.722 ; 18$, regression coefficient $=1.48 \pm 0.125$, linear correlation coefficient $=0.786$ 
Table 5 Analysis of covariance of leaf length and leaf width between families, F3 generation, rad $^{\text {hem }}$ rad $^{\text {hem }} \times$ Sheffield plant

\begin{tabular}{|c|c|}
\hline Reg. Coeff. & Deviations from $r$ \\
\hline & $\begin{array}{l}\text { Sum of } \\
\text { Squares }\end{array}$ \\
\hline
\end{tabular}

Tribe A

from regression

$\begin{array}{llllll}\text { Between-family regression } & - & & 17 & 14.04 & 0.826\end{array}$

coefficients

$\begin{array}{lllll}\text { Common deviation from } & 2.154 & 1592 & 468.92 & 0.295\end{array}$

regression

Between-family adjusted

means

Total deviation from

regression-within tribe

Regression coefficient/within F17,1575 $=2.9, \mathrm{P}<0.001$

Tribe B

$\begin{array}{lllll}\text { Within-family deviations } & - & 1578 & 490.63 & .311\end{array}$

from regression

$\begin{array}{lllll}\text { Between-family regression } & - & 17 & 17.10 & 1.006\end{array}$

coefficients

Common deviation from $\quad \begin{array}{llll}1.770 & 1595 & 507.73 & 0.318\end{array}$

regression

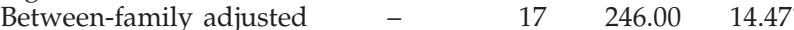

means

Total deviation from

$1.283 \quad 1612 \quad 753.73 \quad-$

regression-within tribe

Regression coefficient/within F17,1578 $=3.23, \mathrm{P}<0.001$

Tribe C

from regression

$\begin{array}{llllll}\text { Between-family regression } & - & 11 & 7.15 & 0.650\end{array}$

coefficients

Common deviation from $2.420 \quad 1595 \quad 576.57 \quad 0.36$

regression

$\begin{array}{lllll}\text { Between-family adjusted } & - & 11 & 147.89 & 13.445\end{array}$

means

Total deviation from $\quad 2.157 \quad 1606 \quad 724.46 \quad-$

regression-within tribe

Regression coefficient/within F11,1584 $=1.81, P>$ or $\sim 0.05$ Adjusted means/within F11,1595 $=37.24, P<<0.001$

Table 6 Factorial analysis of variance of a simulated diallel, containing selfs, backcrosses and intercrosses of selected F4 families

\begin{tabular}{|c|c|c|c|}
\hline Source of variation & $\begin{array}{l}\text { Degrees of } \\
\text { freedom }\end{array}$ & $\begin{array}{l}\text { Sum of } \\
\text { squares }\end{array}$ & $\begin{array}{l}\text { Mean } \\
\text { square }\end{array}$ \\
\hline \multicolumn{4}{|l|}{ Leaf length $\mathrm{L}_{1}$} \\
\hline Maternal strains & 5 & 67.73 & 13.55 \\
\hline Paternal strains & 5 & 66.56 & 13.31 \\
\hline \multicolumn{4}{|c|}{ Maternal $/$ Paternal $=1.02$} \\
\hline \multicolumn{4}{|c|}{ Leaf width W } \\
\hline Maternal strains & 5 & 15.79 & 3.16 \\
\hline Paternal strains & 5 & 17.07 & 3.41 \\
\hline \multicolumn{4}{|c|}{ Maternal $/$ Paternal = 0.93} \\
\hline \multicolumn{4}{|c|}{ Leaf length/width ratio $L_{1} / W$} \\
\hline Maternal strains & 5 & 29.16 & 5.83 \\
\hline Paternal strains & 5 & 32.57 & 6.51 \\
\hline \multicolumn{4}{|c|}{ Maternal $/$ Paternal $=0.90$} \\
\hline \multicolumn{4}{|c|}{ Plant height $\mathrm{H}$} \\
\hline Maternal strains & 5 & 5078.00 & 1015.60 \\
\hline Paternal strains & 5 & 6064.88 & 1212.98 \\
\hline Maternal/Pater & & & \\
\hline
\end{tabular}

Table 7 Means for height and 95\% confidence intervals for F4 selfs, the B1 backcrosses of selected F4 families and for selfs of the original parents in the cross and their $\mathrm{F} 1$, from the diallel experimen

\begin{tabular}{|c|c|c|c|c|}
\hline Family & $\begin{array}{l}\text { Mean, } \\
\text { separated } \\
\text { reciprocals }\end{array}$ & $\begin{array}{c}95 \% \\
\text { confidence } \\
\text { interval }\end{array}$ & $\begin{array}{l}\text { Mean, } \\
\text { combined } \\
\text { reciprocals }\end{array}$ & $\begin{array}{c}95 \% \\
\text { confidence } \\
\text { interval }\end{array}$ \\
\hline S.480,A, self & - & - & 11 & \pm 0.95 \\
\hline S. $480 \times$ hem, B1 & 18 & \pm 1.6 & - & - \\
\hline hem $x$ S.480, B1 & 20 & \pm 1.7 & 19 & \pm 1.2 \\
\hline S. $480 \times$ Sheff., B1 & 16 & \pm 1.0 & - & - \\
\hline Sheff. x S.480, B1 & 16 & \pm 1.4 & 16 & \pm 0.87 \\
\hline S.531,C, self & - & - & 14 & \pm 1.1 \\
\hline S.531 x hem, B1 & 24 & \pm 1.9 & - & - \\
\hline hem x S.531, B1 & 20 & \pm 1.6 & 22 & \pm 1.3 \\
\hline S.531 x Sheff., B1 & 17 & \pm 1.1 & - & - \\
\hline Sheff. x S.531, B1 & 13 & \pm 1.1 & 15 & \pm 0.93 \\
\hline S.541,B, self & - & - & 12 & \pm 0.76 \\
\hline S.541 x hem, B1 & 20 & \pm 1.6 & - & - \\
\hline hem x S.541, B1 & 20 & \pm 1.9 & 20 & \pm 1.2 \\
\hline S.541 x Sheff., B1 & 14 & \pm 0.96 & - & - \\
\hline Sheff. x S.541, B1 & 17 & \pm 0.89 & 16 & \pm 0.71 \\
\hline S.548,B, self & - & - & 9.4 & \pm 0.57 \\
\hline S. $548 \times$ hem, B1 & 21 & \pm 1.5 & - & - \\
\hline hem x S.548, B1 & 22 & \pm 1.5 & 21 & \pm 1.0 \\
\hline S.548 x Sheff., B1 & 13 & \pm 1.0 & - & - \\
\hline Sheff. x S.548, B1 & 17 & \pm 1.3 & 15 & \pm 0.96 \\
\hline hem* self, P1 & - & - & 19 & \pm 1.1 \\
\hline Sheff. ${ }^{* *}$ self, P2 & - & - & 14 & \pm 0.79 \\
\hline hem x Sheff., F1 & 19 & \pm 1.8 & - & - \\
\hline Sheff. $x$ hem, F1 & 23 & \pm 1.9 & 21 & \pm 1.3 \\
\hline
\end{tabular}

hem $=$ hemiradialis line; Sheff. $=$ Sheffield plant

Table 8 Total numbers of plants grown in backcrosses of F3 and F4 families to the hemiradialis line or the Sheffield plant

F3/F4 family in backcross Parent in backcross No. of plants grown
(1) $326+480$
$326+480$
(2) $363+531$
$363+531$
(3) $375+540$
$375+540$
(4) $383+548$
$383+548$
(5) 541
541
(6) 536 536

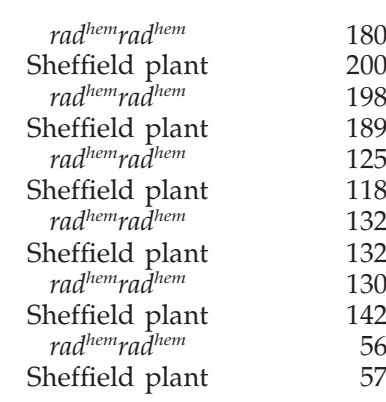

traits defining growth habit and leaf shape suggests that they were not inherited independently of each other; but rather that they were closely integrated parts of, or the expression of, a basic system which is inherited as a unit. There is no evidence for aberrant chromosomal segregation; the F2 and F3 generations were segregating for $\mathrm{rad}^{+} / \mathrm{rad}^{\text {hem }}, \mathrm{El} / \mathrm{El}^{+}, \mathrm{y}^{+} / \mathrm{y}, \mathrm{eos}^{+} /$eos.

The fixation in the F3 of what was considered to be predominantly genetic variation, is, because of its nonsegregant character, assumed to have a cytoplasmic base. The simplest alternative is that only homozygotes for 
growth habit-leaf shape genes were present in the F2 population, an unprecedented homozygote advantage operating in the formation or germination of the F1 seed population. Since seed set in the F1 and germination of the F2 was highly successful, this seems very unlikely.

The F3 effect on families is not due to maternal inheritance, according to the results from reciprocal backcrosses. The conclusions reached from them point to an unusual form of inheritance:

(1) a non-segregating, non-chromosomal, (ie, possibly non-particulate), cytoplasmic factor is postulated to account for the uniformity of F3 families as well as the failure of the distinctive F3 and F4 phenotypes to segregate in the backcrosses; and

(2) approximately equal paternal and maternal contributions to the non-chromosomal factor are postulated to account for the failure of reciprocal backcrosses to show extensive and consistent reciprocal differences in phenotype.

A more precise characterization of the cytoplasmic element in the F2 generation could have led to the concomitant fixation of many more of the traits defining growth habit/leaf shape in the F3. To account for the variety of plant types in the F3, each F2 plant must have characterized the cytoplasmic element in a highly individual way. The genetic background could provide all or part of this individuality, the F3 generation reflecting segregation for genotype in the F2. The greatly increased uniformity within the F3 families may suggest a disproportionate increase in the power of the cytoplasmic element to restrict the expression of genetic segregation. The F4 and F5 support this view, as the succeeding generations showed relatively little change from the type established in the F3. Fixation of the phenotype, as defined in the result section, had probably occurred in this material.

The cytoplasmic element proposed is one having an organismal effect, since most or all morphological traits related to growth habit-leaf shape were affected. The organismal effect is most easily hypothesized in terms of functions of the shoot apical meristem, which initiates all post-embryonic shoot development. It is also known to control degree of branching in many angiosperms and gymnosperms (Cline, 1991) and to control leaf dorsoventrality, as compared with branch actinomorphy in ferns (Wardlaw, 1955; Cutter, 1956; Hicks and Steeves, 1969), and as shown by the induction of centric leaves in lupines (Snow and Snow, 1937) and potatoes (Sussex, 1955). It is also the site of definition of mutant leaf shape in Antirrhinum (Harte and Pohl, 1989), and floral bract and flower symmetry in Antirrhinum (Bergbusch, 1999). As cotyledonary shape was also constant and characteristic within F3 families (visual observation), the role of the presumptive shoot apex and the postulated cytoplasmic element might merge at the stage of cotyledon shape determination or earlier. If the range of phenotypes found in the F2 and F3 from the radialis by Sheffield cross is indeed different from the range in the parallel cross with the hemiradialis allele, a further argument for the involvement of the shoot apical meristem in the F3 effect can be made.

Genes are known to be involved both during the formation of the visible shoot meristem and in its maintenance (Barton and Poethig, 1993; Clark et al, 1996; Laux et al, 1996; Kerstetter and Hake, 1997) and to be differentially active over its expanse (Fleming et al, 1993; Pien et al, 2001).The transformation of a cellular cytoplasmic element or region into a multicellular region with the capacity for initiation of organs, as well as considerable control over their shape and/or rate of development (Steeves and Sussex, 1989; Lyndon, 1990; Sachs, 1991) probably involves many genes. An interaction between maternal and paternal cytoplasmic components which initially 'fixes' or determines the polarity of the zygote (Lyndon, 1990), perhaps in a non-specific way in most known cases, but in a highly specific way in this case, seems a suitable postulate here. The establishment of physiological fields at growth centre(s) at the shoot apex (Steeves and Sussex, 1989) which not only determine the position of leaves formed at the apex (Reinhardt et al, 2000) but also specify leaf shape and growth habit in terms of 'relative field strengths' at significant points in the fields, would allow for the integration of the considerable detail involved in defining each family phenotype in this experiment. This is a useful model as the concept of a field in physical terms suggests the regulative properties, in the embryological sense, actually found in the shoot apical meristem of higher plants (Sussex, 1989), ie, an ability to reconstitute and reorganize itself after considerable division or disturbance, the properties of a developmental 'organizer' (Ball, 1980).

Manipulative experiments on somatic carrot embryos have provided evidence for polar transport of auxin in late globular, heart and torpedo stage embryos, as well as demonstrating the axial nature of a regulative regenerative potential in these early embryonic stages (Schiavone, 1988; Schiavone and Racusen, 1990, 1991). The development of polar growth in globular somatic embryos treated with transport inhibitors was entirely blocked. Polar transport of auxin has long been implicated in shoot apical dominance (Cline, 1991) and these results suggest that dominance-like activity may also be established at a very early stage, even prior to development of a discrete shoot apical meristem in terms of cell and tissue differentiation (Barton and Poethig, 1993).

Polar transport of auxin has been traced back to globular stage zygotic embryos in Brassica juncea also and connected with cotyledon development by Liu et al (1993). Their results indicated that auxin transport was not required for development of the longitudinal, polarized embryo axis but was required for the development of normal dorsoventral, discrete cotyledons, which in the presence of auxin transport inhibitors fused to form a cylinder around the tip. Leaf fusion in Lupinus (Varnell and Vasil, 1978) and bract and flower fusion in Antirrhinum (Bergbusch, 1999) were found after localised application of auxins to post-embryonic shoot apical meristems. Cooke and coworkers in an overview of some of these and other results have suggested that possibly two overlapping mechanisms for the establishment of the embryonic axis may exist, one operative only in zygotic embryos (a positional mechanism), the other the sole mechanism in somatic embryos (an auxin-mediated mechanism), and that the former arises as a persistent maternal effect (Cooke et al, 1993). This does not altogether coincide with the F3 effect on growth habit/leaf shape in these families and their behaviour in backcrosses, as a maternal bias was not found in these populations. 
Another question may be whether the fixation of morphological phenotype within families or its variety between families should be stressed. The outcross between two simple, true breeding types produced a large number of non-identical plants in the F2. None of these highly visible variations appeared in selfs of the parent plants, which suggests that the new variation was due to recombination between a relatively large number of genes. Individual genes were not identified and pleiotropic effects of individual genes cannot be ruled out in assessing how many genes were involved. Another possibility is that one of the parent plants (probably the Sheffield plant) was itself a 'fixed' line, containing much genetic heterozygosity. This could account for the F2 effect. The molecular level of organization is usually analysed in the empirical tests of heterozygosity, eg, allozyme heterozygosity. This may persist in the uniform F3 'populations' described in this paper, but remain unexpressed morphologically under the regime of a highly specified organizer and hence not selected for or against at that level.

The selective advantage that drives the postulated organizer may not be heterosis, but the conservation of the developmental property of organization at the organismal level and its efficiency, compared with a postulated 'unorganized' initial state which requires a stepwise (therefore possibly error-prone) development of organization at each level of the hierarchy, from possible physical/chemical restraints and differentially activated genes spatially (Meinhardt, 1984; Lyndon, 1990). The breakdown of the fixation of the growth habit/leaf shape complex would not necessarily mean a fundamental change in the inheritance of the organizer as such, but in its degree of specificity, which might then be re-established during several generations of selfing. The breakdown and re-specification of the relatively fixed element(s) derived from the parent(s) in this cross may have been due to a fundamental incompatibility between elements of the organizer derived from the inbred line and the Sheffield plant.

\section{Acknowledgements}

The research reported in this paper was done at a number of universities, including Cambridge University, Cambridge, UK and McGill University, Montreal, Canada. I would like to thank Professor JM Thoday for suggesting and providing the material. The research was mainly supported by National Research Council of Canada.

\section{References}

Ball E (1980). Regeneration from isolated portions of the shoot apex of Trachymene coerulea R C Grah. Ann Bot (Lond) 45: 103-112.

Barton MK, Poethig RS (1993). Formation of the shoot apical meristem in Arabidopsis thaliana: an analysis of development in the wild type and in the shoot meristemless mutant. Development 119: 823-831.

Bergbusch VL (1999). A note on the manipulation of flower symmetry in Antirrhinum majus. Ann Bot (Lond) 83: 483-488.

Clark SE, Jacobsen SE, Levin JZ, Meyerowitz EM (1996). The Clavata and Shoot Meristemless loci competitively regulate meristem activity in Arabidopsis. Development 122: 1567-1575.

Cline MG (1991). Apical dominance. Bot Rev 57: 318-358.

Cooke TJ, Racusen RH, Cohen JD (1993). The role of auxin in plant embryogenesis. Plant Cell 5: 1494-1495.
Cutter EG. (1956). Experimental and analytical studies of pteridophytes. XXXIII. The experimental induction of buds from leaf primordia in Dryopteris aristata. Druce. Ann Bot (Lond) 20: 143-165.

Fleming AJ, Mandel T, Roth I, Kuhlemeier C (1993). The patterns of gene expression in the tomato shoot apical meristem. Plant Cell 5: 297-309.

Giessmann TA, Jorgensen EC, Johnson L (1954). The chemistry of flower pigmentation in Antirrhinum majus. I. The flavonoid components of the homozygous P, M, Y color types. Arch Biochem Biophys 49: 368-388.

Harte C, Meinhard T (1979). Phänogenetik der Blattform bei Antirrhinum majus L. 2. Das allometrische Wachstum bei verschiedenen Umweltbedingungen. Biol Zbl 98: 203-219.

Harte C, Meinhard T (1980). Phänogenetik der Blattform bei Antirrhinum majus L. 4. Die Frühentwicklung der Blattanlagen bei Sippe 50 und 9 Blattformmutanten. Biol Zbl 99: 183-205.

Harte C, Pohl H (1989). Phänogenetik der Blattform bei Antirrhinum majus L.10. Parameter der Wachstumsfunktion und Wachstumskriterien der Blätter der Sippe 50 und einiger Mutanten in verschiedenen Umweltbedingungen. Biol $\mathrm{Zbl}$ 108: 123-152.

Hicks GS, Steeves TA (1969). In vitro morphogenesis in Osmunda cinnomomea. The role of the shoot apex in early development. Can J Bot 47: 575-580.

Jinks JL (1954). The analysis of continuous variation in a diallele cross of Nicotiana rustica varieties. Genetics 39: 767-788.

Kerstetter RA, Hake S (1997). Shoot meristem formation in vegetative development. Plant Cell 9: 1001-1010.

Laux T, Mayer KFX, Berger J, Jürgens G 1996. The Wuschel gene is required for shoot and floral meristem integrity in Arabidopsis. Development 122: 87-96.

Liu C-M, Xu Z-H, Chua N-H (1993). Auxin polar transport is essential for the establishment of bilateral symmetry during early plant embryogenesis. Plant Cell 5: 621-630.

Lyndon RF (1990). Plant development. The cellular basis. Unwin Hyman: London.

Meinhardt H (1984). Models of pattern formation and their application to plant development. In: Barlow PW, Carr DJ (eds) Positional Controls in Plant Development. Cambridge University Press: Cambridge. pp 1-32.

Pien S, Wyrzykowska J, Fleming AJ (2001). Novel marker genes for early leaf development indicate spatial regulation of carbohydrate metabolism within the apical meristem. Plant J 25: 663-674.

Reinhardt D, Mandel T, Kuhlemeier C (2000). Auxin regulates the initiation and radial position of plant lateral organs. Plant Cell 12: 507-518.

Sachs T (1991). Pattern Formation in Plant Tissues. Cambridge University Press: Cambridge.

Schiavone FM (1988). Microamputation of somatic embryos of the domestic carrot reveals apical control of axis elongation and root regeneration. Development 103: 657-664.

Schiavone FM, Racusen RH (1990). Microsurgery reveals regional capabilities for pattern reestablishment in somatic carrot embryos. Dev Biol 141:211-219.

Schiavone FM, Racusen RH (1991). Regeneration of the root pole in surgically transected carrot embryos occurs by positiondependent, proximodistal replacement of missing tissues. Development 113: 1305-1313.

Snedecor GW (1956). Statistical Methods, 5th edn. The Iowa State University Press: Ames, Iowa.

Snow M, Snow R (1937). Auxin and leaf formation. New Phytol 36: $1-18$

Steeves TA, Sussex IM (1989). Patterns in Plant Development, 2nd edn. Cambridge University Press: Cambridge.

Stubbe H (1966). Genetik und zytologie von Antirrhinum L. sect. Antirrhinum. VEB Gustav Fischer Verlag: Jena.

Sussex IM (1955). Morphogenesis in Solanum tuberosum. Experimental investigation of leaf dorsiventrality and orientation in the juvenile shoot. Phytomorphology 5: 286-300. 
Sussex IM (1989). Developmental programming of the shoot meristem. Cell 56: 225-229.

Varnell RJ, Vasil IK (1978). Experimental studies of the shoot apical meristem of seed plants. 1. Morphological and cytochemical effects of IAA applied to the exposed meristem of Lupinus albus. Am J Bot 65: 40-46.
Wardlaw CW (1955). Experimental and analytical studies in pteridophytes. XXVIII. Leaf symmetry and orientation in ferns. Ann Bot (Lond) 19: 389-399.

Wearden S (1964). Alternative analyses of the diallele cross. Heredity 19: 669-680. 